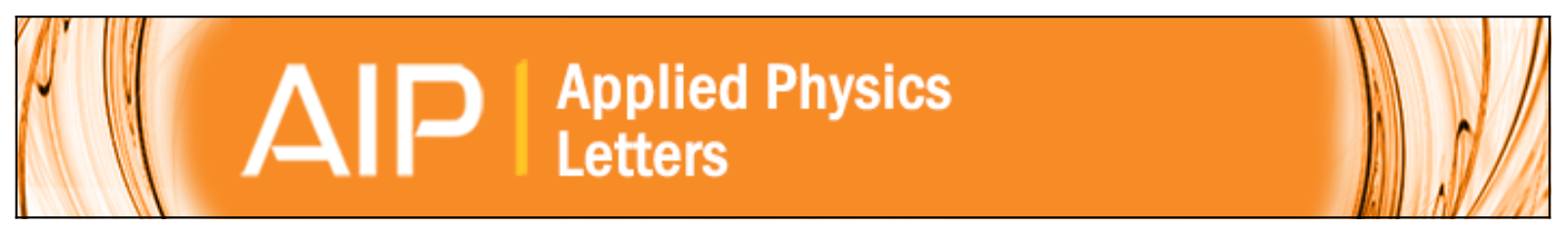

\title{
Light-induced performance increase of silicon heterojunction solar cells
}

Eiji Kobayashi, Stefaan De Wolf, Jacques Levrat, Gabriel Christmann, Antoine Descoeudres, Sylvain Nicolay, Matthieu Despeisse, Yoshimi Watabe, and Christophe Ballif

Citation: Applied Physics Letters 109, 153503 (2016); doi: 10.1063/1.4964835

View online: http://dx.doi.org/10.1063/1.4964835

View Table of Contents: http://scitation.aip.org/content/aip/journal/apl/109/15?ver=pdfcov

Published by the AIP Publishing

\section{Articles you may be interested in}

Plasma-initiated rehydrogenation of amorphous silicon to increase the temperature processing window of silicon heterojunction solar cells

Appl. Phys. Lett. 109, 031601 (2016); 10.1063/1.4958831

Three-dimensional numerical analysis of hybrid heterojunction silicon wafer solar cells with heterojunction rear point contacts

AIP Advances 5, 077124 (2015); 10.1063/1.4926809

In situ photoluminescence system for studying surface passivation in silicon heterojunction solar cells

J. Vac. Sci. Technol. A 33, 021201 (2015); 10.1116/1.4902014

Amorphous silicon oxide window layers for high-efficiency silicon heterojunction solar cells

J. Appl. Phys. 115, 024502 (2014); 10.1063/1.4861404

Efficient heterojunction solar cells on $\mathrm{p}$-type crystal silicon wafers

Appl. Phys. Lett. 96, 013507 (2010); 10.1063/1.3284650

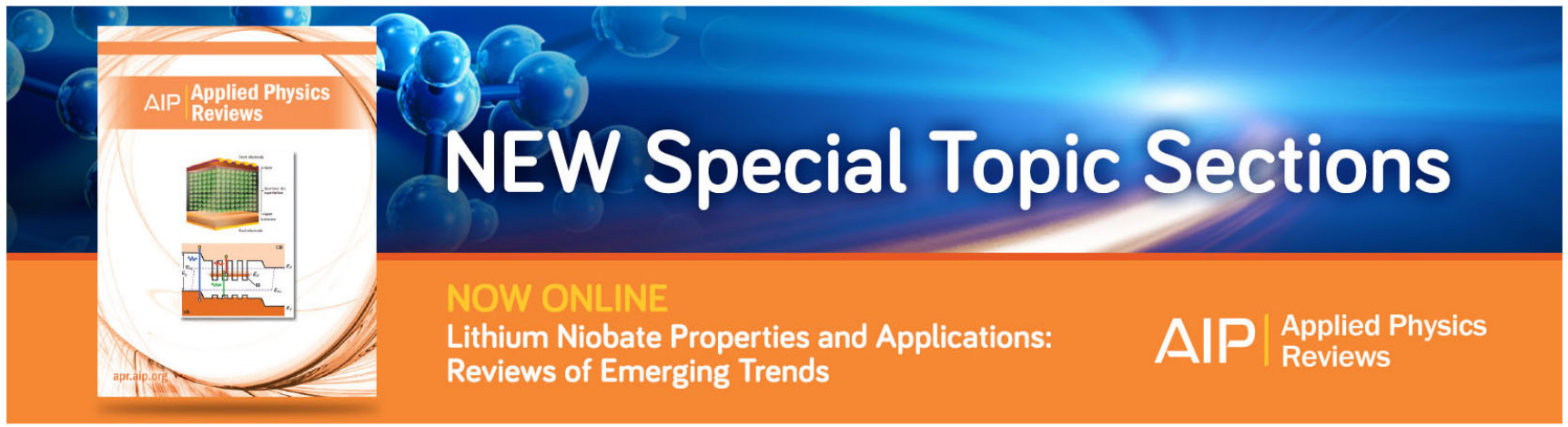




\title{
Light-induced performance increase of silicon heterojunction solar cells
}

\author{
Eiji Kobayashi, ${ }^{1,2,3, a)}$ Stefaan De Wolf, ${ }^{4}$ Jacques Levrat, ${ }^{5}$ Gabriel Christmann, ${ }^{5}$ \\ Antoine Descoeudres, ${ }_{5}^{5}$ Sylvain Nicolay, ${ }^{5}$ Matthieu Despeisse, ${ }^{5}$ Yoshimi Watabe, ${ }^{2}$ \\ and Christophe Ballif ${ }^{1,5}$ \\ ${ }^{1}$ École Polytechnique Fédérale de Lausanne (EPFL), Institute of Microengineering (IMT), Photovoltaics \\ and Thin Film Electronics Laboratory, Rue de la Maladière 71b, CH-2002 Neuchâtel, Switzerland \\ ${ }^{2}$ Choshu Industry Co., Ltd., 3740, Shin-yamanoi, Sanyo Onoda, Yamaguchi 757-8511, Japan \\ ${ }^{3}$ Department of Materials Science and Engineering, Yamaguchi University, 2-16-1 Tokiwadai, Ube, \\ Yamaguchi 755-8611, Japan \\ ${ }^{4}$ King Abdullah University of Science and Technology (KAUST), KAUST Solar Center (KSC), Thuwal, \\ 23955-6900, Saudi Arabia \\ ${ }^{5}$ CSEM PV-Center, Jaquet-Droz 1, CH-2002 Neuchâtel, Switzerland
}

(Received 9 September 2016; accepted 1 October 2016; published online 11 October 2016)

\begin{abstract}
Silicon heterojunction solar cells consist of crystalline silicon (c-Si) wafers coated with doped/ intrinsic hydrogenated amorphous silicon $(a-\mathrm{Si}: \mathrm{H})$ bilayers for passivating-contact formation. Here, we unambiguously demonstrate that carrier injection either due to light soaking or (dark) forwardvoltage bias increases the open circuit voltage and fill factor of finished cells, leading to a conversion efficiency gain of up to $0.3 \%$ absolute. This phenomenon contrasts markedly with the light-induced degradation known for thin-film $a$-Si:H solar cells. We associate our performance gain with an increase in surface passivation, which we find is specific to doped $a-\mathrm{Si}: \mathrm{H} / c-\mathrm{Si}$ structures. Our experiments suggest that this improvement originates from a reduced density of recombination-active interface states. To understand the time dependence of the observed phenomena, a kinetic model is presented. Published by AIP Publishing. [http://dx.doi.org/10.1063/1.4964835]
\end{abstract}

Hydrogenated amorphous silicon $(a-\mathrm{Si}: \mathrm{H})$ is an amorphous semiconductor with important applications in thinfilm silicon solar cells ${ }^{1}$ and flat-panel displays. ${ }^{2}$ In recent years, $a$-Si:H layers also garnered significant attention, thanks to their excellent crystalline silicon $(c-\mathrm{Si})$ surface passivation properties, even when only a few nm thin. ${ }^{3-8}$ This property is exploited with remarkable success for passivating-contact fabrication in silicon heterojunction (SHJ) solar cells, ${ }^{9-22}$ with reported conversion cell efficiencies as high as $26.3 \% .^{23}$

For any solar cell technology, an important criterion for ultimate device performance is its stability under prolonged light exposure. In this context, the boron-oxygen defect complex active in $p$-type $c$-Si wafers is known to lead to a lightinduced degradation (LID) in industrial $c$-Si solar cells. ${ }^{24,25}$ Another classic example is the LID of thin-film $a$-Si:H solar cells. The latter is usually attributed to the generation of deep defects that act as recombination centers, ${ }^{26}$ and is commonly referred to as the Staebler-Wronski effect (SWE). ${ }^{27-31}$ Crystalline Si surfaces coated with intrinsic $a$-Si:H films were found to suffer as well from a degradation in surface passivation during prolonged light soaking (LS). ${ }^{32}$ Kinetically, this degradation follows so-called power laws of a similar form as for bulk $a$-Si:H, suggesting that the intrinsic $a$-Si:H/c-Si interface equally suffers from SWE. ${ }^{33,34}$ Interestingly, $c$-Si surfaces coated with $p$-type $a$-Si:H films or bilayers of $p$-type/intrinsic $a$-Si:H were reported to increase their surface passivation during LS. ${ }^{35}$ These reports raise the concern whether finished SHJ solar cells are stable under actual operating conditions. In this context, we report here on the LS of finished SHJ devices, which—remarkably—results

${ }^{\text {a) E-mail: kobayashi.eiji@choshu.co.jp }}$ in improved performance. Our investigation reveals that this phenomenon is caused by carrier recombination, which can occur through either device biasing or LS. We show here that improved surface passivation is responsible for the effect and takes place when applying LS to the passivating contacts in our devices. This improvement contrasts with the LS losses associated with the intrinsic $a-\mathrm{Si}: \mathrm{H} / c-\mathrm{Si}$ interface, lacking doped overlayers. We discuss the observed phenomena in the context of the SWE, and underline their importance for the industrialization of SHJ solar technology.

As we observed identical results on Czochralski $(\mathrm{Cz}) \mathrm{Si}$ and float-zone $\mathrm{Si}$ (data not shown), we focus in this study

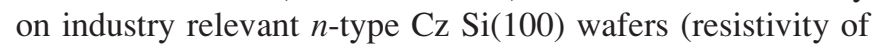
$2.9 \Omega \mathrm{cm}$ ), used as absorbers for SHJ solar cell fabrication. These wafers were textured in an alkaline solution and wetchemically cleaned. The textured wafers (thickness of $180 \mu \mathrm{m}$ ) were then dipped in 5\% HF solution just before plasma-enhanced chemical vapor deposition (PECVD). The intrinsic ( $i$ ) and doped ( $n$ and $p$ ) $a$-Si:H layers were deposited on both wafer surfaces at $200{ }^{\circ} \mathrm{C}$ using mixtures of $\mathrm{SiH}_{4}, \mathrm{PH}_{3}$, $\mathrm{B}\left(\mathrm{CH}_{3}\right)_{3}$, and $\mathrm{H}_{2}$ in a PECVD tool, operated at $13.56 \mathrm{MHz}$. We used $i$ layers thickness of $10 \mathrm{~nm}$ for test structures and $7 \mathrm{~nm}$ for finished cell structures when capped by doped over layers and thickness of $25 \mathrm{~nm}$ for a test structure without doped over layers and $n$ and $p$ layers thickness of $10 \mathrm{~nm}$ for test structures, and $5 \mathrm{~nm}$ for finished cell structures. Samples featuring different types of (bi-)layers were studied, including the symmetric structures $i / i, i-p / i-p$, and $i-n / i-n$, as well as the asymmetric solar cell precursor $i-p / i-n$. For finished cells (size of $243.4 \mathrm{~cm}^{2}$ ), indium tin oxide (ITO) films were sputterdeposited on both wafer sides, which was then capped with a silver reflector at the rear, also sputter-deposited. Front electrodes (fingers and 3 busbars) were screen-printed from a low 
temperature silver paste on the front ITO layer. Finally, the cells were cured at $200^{\circ} \mathrm{C}$ for $30 \mathrm{~min}$.

Light soaking was carried out in a commercial system (Sunirad A-65, Solaronix) under 1-sun illumination. The substrate temperature was kept constant at $32 \pm 2{ }^{\circ} \mathrm{C}$ by a water cooling system. After LS and characterization, postannealing was carried out at $200{ }^{\circ} \mathrm{C}$ in air in the dark. To track the electronic changes at the $a-\mathrm{Si}: \mathrm{H} / c-\mathrm{Si}$ interface, excess carrier lifetimes, $\tau_{\text {eff }}$, of the wafers were measured with the photo-conductance method in transient mode (WCT-120, Sinton Instruments), which complies with SEMI standard PV-13. ${ }^{36}$ The finished SHJ cells were characterized by current-voltage measurements on a 1-sun solar simulator under Air Mass 1.5 global illumination. The measurement errors expected to be less than $\pm 0.6 \%$ relative.

Figure 1(a) illustrates how light soaking of cells in open-circuit conditions leads to an increase of conversion cell efficiency $(\eta)$ of finished SHJ solar cells. In this graph, $t_{1-\text { sun }}$ is the 1 -sun LS time. A typical $\eta$ gain of $0.3 \%$ absolute is observed during LS as a result of an increasing opencircuit voltage $\left(V_{o c}\right)$ and fill factor $(F F)$. The maximum, minimum, and standard deviation of the $\eta$ gain are $0.39 \%$, $0.27 \%$, and $0.045 \%$, respectively, where their values reach saturation. Similar increases are observed for various temperature sets $\left(25-75^{\circ} \mathrm{C}\right)$ during LS. Furthermore, we investigated the effect of carrier injection under (dark) forwardvoltage bias using the finished SHJ solar cells. Figure 1(b) shows the normalized $\eta$ under forward-voltage bias at $2.8 \mathrm{~V}$ and $41 \mathrm{~mA} \mathrm{~cm}{ }^{-2}$ with no illumination, compared with LS results. In this graph, $t_{\text {bias }}$ is the forward-bias application time. Notably, a similar improvement of $\eta$ is observed under
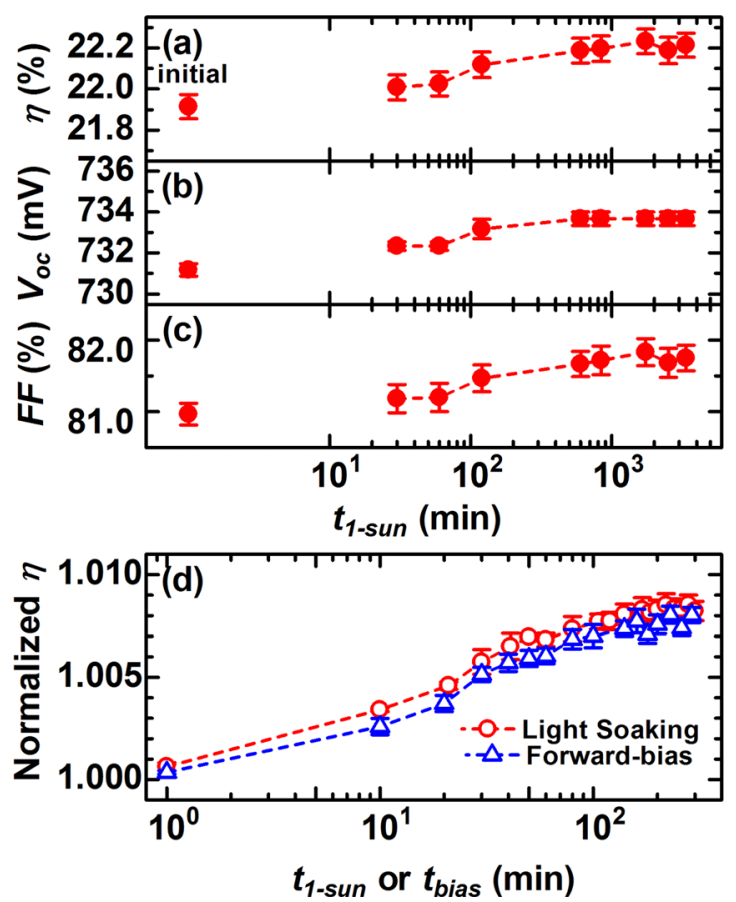

FIG. 1. Measured values for $\eta$ of SHJ solar cells. The values represent averaged characteristics. Each error bar represents standard error. (a)-(c) An effect of prolonged light exposure as function of $t_{1-\text { sun }}$. Total cell numbers are six. (d) A comparison of light-induced and forward-bias-induced carrier injection in rear-emitter cells as function of $t_{1-\text { sun }}$ and $t_{\text {bias }}$, respectively. Each value is normalized at an initial value of $\eta$ in each cell. Total cell numbers of each condition are three. forward-bias condition as for LS. This result indicates that the performance increase of SHJ cells is caused by carrier injection, and likely is the result from the recombination of generated electron-hole pairs at the interfaces.

Next, we turn to the analysis of the specific interfaces present in our devices. By comparing samples with $a$-Si:H layers, with and without ITO overlayer, we exclude a significant contribution of the $a$-Si:H/ITO interface to the observed effects. We then focused on the $a-\mathrm{Si}: \mathrm{H} / c$-Si interfaces, using samples without ITO overlayer. Figure 2 shows how the $a-\mathrm{Si}: \mathrm{H} / c-\mathrm{Si}$ interface passivation evolves during repeated LS/annealing cycles for the different test structures. In this graph, $t_{a n n}$ is the annealing time. For reference, the surface passivation of the $i / i$ structures is seen to degrade during LS (recovered by subsequent annealing). This phenomenon is in accordance with our earlier reports, and was explained in the framework of the SWE. ${ }^{33,34}$ Considering now the case of wafers passivated with doped/intrinsic $a$-Si:H bilayers (i.e., the $i-p / i-n, i-p / i-p$, and $i-n / i-n$ samples), it is seen that their $\tau_{\text {eff }}$ values increase during LS to reach saturation after about $85 \mathrm{~h}$, which is a remarkable result. At saturation, the $\tau_{\text {eff }}$ values of the $i-p / i-n, i-p / i-p$, and $i-n / i-n$ samples are, respectively, $60 \%, 40 \%$, and $17 \%$ higher than their initial state. These trends are quite similar to what Mahtani et al. reported for $p$-type/intrinsic $a$-Si:H bilayers. ${ }^{35}$ We note that, during subsequent annealing (after LS), the $\tau_{\text {eff }}$ value increases for the $i-n / i-n$ structures, whereas it slightly decreases for the $i-p /$ $i-n$ and $i-p / i-p$ structures. This asymmetric phenomenon is likely caused by Fermi-level induced defect formation in $a$-Si:H films during annealing. ${ }^{37}$ Notably, this $\tau_{\text {eff }}$ loss is subsequently recovered by additional LS.

Figure 3 shows $\tau_{\text {eff }}$ curves as a function of the carrier injection level, $\Delta n$, during LS of the symmetric $i-p / i-p$ and $i-n / i-n$ structures. Calculated $\tau_{\text {eff }}$ curves, based on an $a-\mathrm{Si}: \mathrm{H} /$ $c$-Si interface recombination model, ${ }^{38}$ were fitted to these measurements. The formalism used for these calculations has two model parameters, namely, the interface state density, $N_{s}$, and the interface charge density, $Q_{s}$. The interface states are considered to be silicon dangling bonds, which are amphoteric, with associated capture cross sections for electrons and holes $\left(\sigma_{n}{ }^{+}\right.$and ${\sigma_{p}}^{-}$for the charged states, and $\sigma_{n}{ }^{O}$ and $\sigma_{p}{ }^{0}$ for the neutral states, respectively; see also Ref. 38). The capture cross section ratios were taken to be $\sigma_{n}{ }^{0} / \sigma_{p}{ }^{0}=1 /$ 20 and $\sigma_{n}{ }^{+} / \sigma_{n}{ }^{0}=\sigma_{p}{ }^{-} / \sigma_{p}{ }^{0}=500$, following Olibet et al. ${ }^{38}$ Figure 3 shows that the experimental LS data can be fitted well by the employed calculations. The uppermost solid curve represents the maximum bulk lifetime based on the

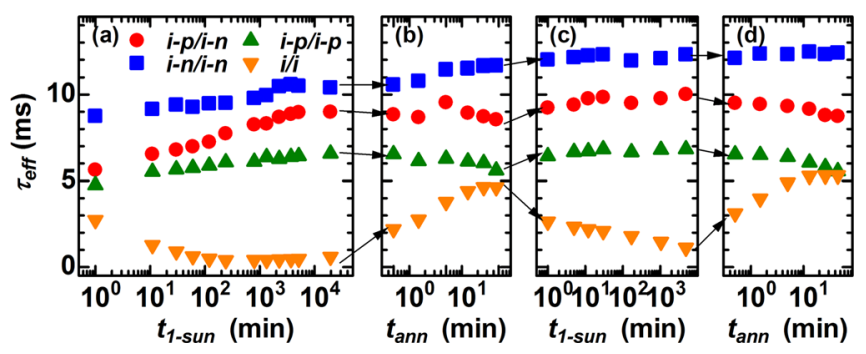

FIG. 2. Minority carrier lifetime evolution during two repeated cycles of 1-sun LS (a) and (c) and $200^{\circ} \mathrm{C}$ annealing (b) and (d) for four different structures. Evaluation was performed at $\Delta n=\Delta p=1 \times 10^{15} \mathrm{~cm}^{-3}$. 


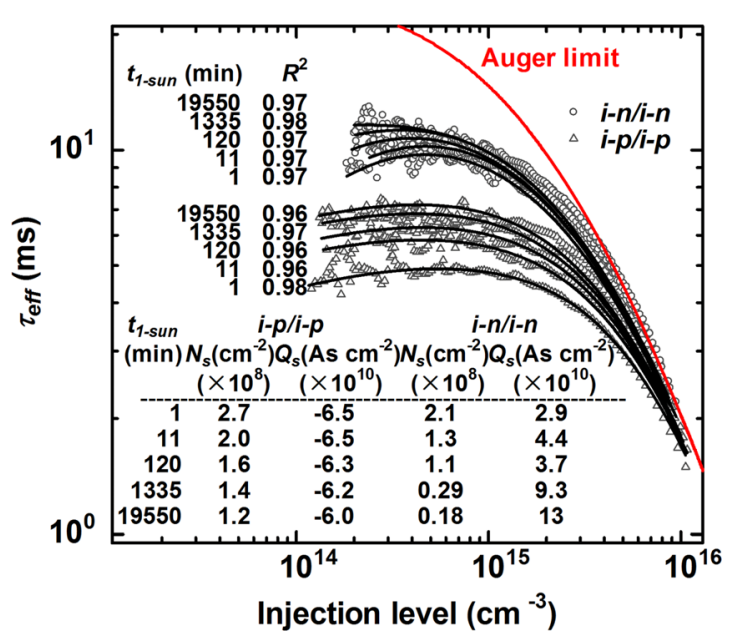

FIG. 3. Measured values for $\tau_{\text {eff }}$ as function of the carrier injection level. The different curves show data after different LS times. Symbols represent measured data, whereas solid lines show calculated recombination-model fits. Values for the fitting parameters are given in the inset table. Values for coefficient of determination $\left(R^{2}\right)$ are given in the figure.

Auger recombination parameterization by Richter et al. ${ }^{39}$ From the fitting results it follows that the light-induced changes in $\tau_{\text {eff }}$ of $i-p / i$ - $p$ structures are mainly driven by a decreasing $N_{s}$ value (without much of a change in $Q_{s}$ ); for the $i-n / i-n$ structures, both parameters $N_{s}$ and $Q_{s}$ are seen to change over LS.

Figure 4 analyses in greater detail the kinetics underlying our LS data. Surface passivation kinetics under LS conditions were already discussed earlier for the case of intrinsic $a$-Si:H passivation layers, which degrade during $\mathrm{LS}^{33,34}$ This was found to be driven by an increase in $N_{s}$, which in turn was found to obey a power law, ${ }^{33}$ showing essentially identical kinetics as known for the light-induced degradation

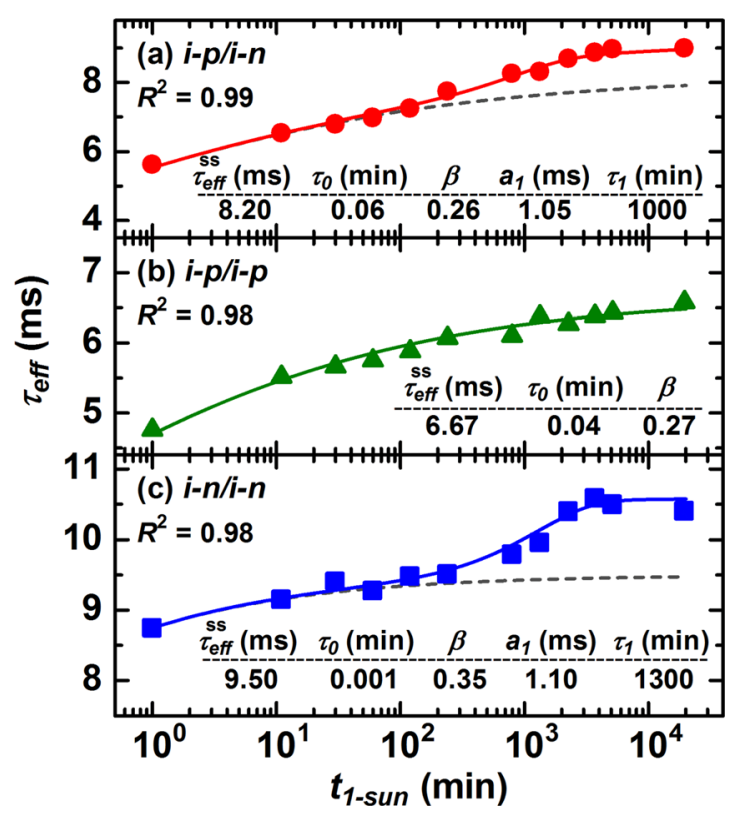

FIG. 4. Measured values for $\tau_{\text {eff }}$ as function of $t_{1 \text {-sun }}$. Evaluation was performed at $\Delta n=\Delta p=1 \times 10^{15} \mathrm{~cm}^{-3}$. Symbols represent measured data, whereas solid lines show (a) and (c) power law and field effect fits and (b) power law to the data. Dashed lines show the part of the power law only. Values for the fitting parameters are given in the inset table. Values for coefficient of determination $\left(R^{2}\right)$ are given in the figure. occurring in bulk $a$-Si:H films. ${ }^{40}$ Such similarity strongly suggests that the intrinsic $a-\mathrm{Si}: \mathrm{H} / c-\mathrm{Si}$ interface (i.e., the $i / i$ structure) also suffers from the SWE. ${ }^{33}$ Returning to the $i$ - $p /$ $i$ - $p$ structure, we derived from Figure 3 that LS again mainly affects $N_{s}$ (by decreasing its value this time, however). In Figure 4(b), we show that the kinetics occurring at the $i-p / i-p$ interfaces can be fitted as well to power laws, of slightly different form

$$
\tau_{e f f}\left(t_{1-\text { sun }}\right)=\tau_{e f f}^{S S} /\left(1+\left(\frac{t_{1-\text { sun }}}{\tau_{0}}\right)^{-\beta}\right),
$$

where $\tau_{\text {eff }}^{S S}$ is the saturation value for $\tau_{\text {eff }}$, and $\beta$ and $\tau_{O}$ are the dispersion parameter $(0<\beta<1)$ and effective time constant, respectively. The data of the samples featuring $i-n / i-n$ structures cannot be fitted well by this law as shown in Figure 4(c) (dashed line), which is not a surprise, as in this case $Q_{s}$ changes. [Once a sufficiently low $N_{s}$ is reached $\left(<1 \times 10^{8}\right.$ $\mathrm{cm}^{-2}$ ) at the $a-\mathrm{Si}: \mathrm{H} / c-\mathrm{Si}$ interface (see Figure 3)].

To find a law that possibly can fit the observed kinetics of samples featuring the $i-n / i-n$ structure, inspiration can be taken from light-soaking studies of a quite different passivation layer, namely, $\mathrm{Al}_{2} \mathrm{O}_{3}$, which mainly relies on a negative fixed-charge field effect. ${ }^{41}$ For this interface, improved passivation by LS was explained by an increase in negative interface charge caused by internal photoemission of electrons during LS. ${ }^{33}$ Liao et al. proposed that the improvement of $\tau_{\text {eff }}$ follows: ${ }^{42}$

$$
\tau_{\text {eff }}\left(t_{1-\text { sun }}\right)=a_{0}+\sum_{i=1}^{m} a_{i}\left(1-\exp \left(-\frac{t_{1-\text { sun }}}{\tau_{i}}\right)\right),
$$

where $a_{O}$ and $a_{i}$ are constants related to initial and final $\tau_{\text {eff }}$ and $\tau_{i}$ is effective time constant, with trapping sites (at least two sites of fast and slow traps, respectively) that are located at $\mathrm{SiO}_{\mathrm{x}} / \mathrm{Al}_{2} \mathrm{O}_{3}$ interface. $^{42,43}$ The trapping of the electron results in an increase of negative fixed charge density in the $\mathrm{Al}_{2} \mathrm{O}_{3}$ film. ${ }^{44}$ To test if this expression can be translated into the context of the $a-\mathrm{Si}: \mathrm{H} / c-\mathrm{Si}$ interface, we assume only one type of charge trap present (that may be associated with the silicon dangling bond). The combined time dependence of the $\tau_{\text {eff }}$ may then be expressed as

$$
\begin{aligned}
\tau_{\text {eff }}\left(t_{1-\text { sun }}\right)= & \tau_{\text {eff }}^{S S} /\left(1+\left(\frac{t_{1-\text { sun }}}{\tau_{0}}\right)^{-\beta}\right) \\
& +a_{1}\left(1-\exp \left(-\frac{t_{1-\text { sun }}}{\tau_{1}}\right)\right)
\end{aligned}
$$

where $a_{1}$ is a constant and $\tau_{1}$ is an effective time constant. The two terms in this expression account for $N_{s}$ and $Q_{s}$ related changes, respectively. The data in Figure 4 show that this expression fits all experimental data very well. Data fitting was obtained by fixing the initial/final $\tau_{\text {eff }}$ values during LS.

We now briefly speculate on the origins of our observations. Classically, the SWE was mainly discussed for bulk $a$-Si:H. Stutzmann proposed an elegant model explaining its metastability under light soaking and annealing, where a weak covalent $\mathrm{Si}-\mathrm{Si}$ bond can reversibly be transformed 
into two Si dangling bonds. ${ }^{45}$ The energy required for such rupture is supplied by the recombination of a photogenerated charge-carrier pair, whereas subsequent annealing repairs the broken bonds into weak bonds, improving the material quality. In this way, under steady-state conditions (dark or light), the initial deep state density $\left(N_{0}\right)$ establishes an equilibrium, dictated by the weak-bond density $\left(N_{\mathrm{ss}}\right)$. The latter is related to the Urbach energy $E_{0}$, which expresses the "disorder" of the material, and is processing specific. Kinetically, this recombination-driven process also enabled to analytically explain the often observed power laws for the SWE. ${ }^{40}$

Notably, most studies dealing with the SWE only considered intrinsic $a$-Si:H and see that $N_{\mathrm{ss}}>N_{0}$. However, recently Scuto et al. reported improved performance of reversely biased thin-film $a$-Si:H modules under prolonged illumination. ${ }^{46}$ This is an important observation for our work, because the capping of intrinsic $a$-Si:H buffer layers with doped over-layers also moves their Fermi-level closer to one of the band edges. ${ }^{37}$ Taking these arguments together, it is tempting to conclude that shifting the Fermi-level close to either conduction or valence band may revert the SWE from an electronic degradation to an improvement process. Further work is needed to consolidate this view.

In this paper, we have presented the effect of LS for $n$-c-Si passivated by $i$ - $a$-Si:H films with $p$ - and $n$-type doped layers. An increase of $\tau_{\text {eff }}$ results in improving $V_{o c}$ and $F F$ of finished SHJ cells after LS as well as application of dark forward-voltage bias, corresponding to $0.3 \%$ absolute gain of $\eta$ or roughly $1.4 \%$ relative. The $\tau_{\text {eff }}$ curve fitting suggests that the LS improvement originates from a reduced density of recombination-active interface states. We find that the time dependence behavior of the $\tau_{\text {eff }}$ values for doped $a$ $\mathrm{Si}: \mathrm{H} / c-\mathrm{Si}$ structures is described by a modified power law. Finally, we note that these findings bear high relevance to industrial production, as the samples used in this study were made using industry compatible processes. It is hence expected that modules made out of such solar cells will show a similar gain in the range of $0.3 \%$ absolute. A $20 \%$ efficiency module flashed at the exit of a production line with $320 \mathrm{~W}$ could, for instance, be rated at $324.5 \mathrm{~W}$, following light exposure. For a $1 \mathrm{GW}$ production line, this would correspond to $14 \mathrm{MW}$ annual excess production, with a market value in the range of 7-10 million US dollars.

The authors gratefully acknowledge Jan Haschke, Silvia Martin de Nicolas, Raphaël Monnard, Jean Cattin, Andrea Tomasi, Gizem Nogay, Andrea Ingenito, Philipp Löper, Franz-Josef Haug, Philipp Wyss, Josua Stuckelberger, Jonathan Champliaud, and Christophe Allebé for fruitful discussions. Financial support of Swiss Federal Office of Energy, EU FP7 program (CHETAAH Project, Contract No. 609788), and King Abdullah University of Science and Technology (KAUST) is acknowledged.

${ }^{1}$ A. Shah, P. Torres, R. Tscharner, N. Wyrsch, and H. Keppner, Science 285, 692 (1999).

${ }^{2}$ R. A. Street, Adv. Mater. 21, 2007 (2009).

${ }^{3}$ B. M. George, J. Behrends, A. Schnegg, T. F. Schulze, M. Fehr, L. Korte,

B. Rech, K. Lips, M. Rohrmueller, E. Rauls, W. G. Schmidt, and U. Gerstmann, Phys. Rev. Lett. 110, 136803 (2013).
${ }^{4}$ H. Fujiwara and M. Kondo, Appl. Phys. Lett. 90, 013503 (2007).

${ }^{5}$ S. De Wolf and M. Kondo, Appl. Phys. Lett. 90, 042111 (2007).

${ }^{6}$ J. Geissbuehler, S. De Wolf, B. Demaurex, J. P. Seif, D. T. L. Alexander, L. Barraud, and C. Ballif, Appl. Phys. Lett. 102, 231604 (2013).

${ }^{7}$ S. De Wolf, S. Olibet, and C. Ballif, Appl. Phys. Lett. 93, 032101 (2008).

${ }^{8}$ S. De Wolf, C. Ballif, and M. Kondo, Phys. Rev. B 85, 113302 (2012).

${ }^{9}$ K. Masuko, M. Shigematsu, T. Hashiguchi, D. Fujishima, M. Kai, N. Yoshimura, T. Yamaguchi, Y. Ichihashi, T. Mishima, N. Matsubara, T. Yamanishi, T. Takahama, M. Taguchi, E. Maruyama, and S. Okamoto, IEEE J. Photovoltaics 4(6), 1433 (2014).

${ }^{10}$ M. Taguchi, A. Yano, S. Tohoda, K. Matsuyama, Y. Nakamura, T. Nishiwaki, K. Fujita, and E. Maruyama, IEEE J. Photovoltaics 4(1), 96 (2014).

${ }^{11}$ J. Geissbühler, J. Werner, S. Martin de Nicolas, L. Barraud, A. HesslerWyser, M. Despeisse, S. Nicolay, A. Tomasi, B. Niesen, S. De Wolf, and C. Ballif, Appl. Phys. Lett. 107, 081601 (2015).

${ }^{12}$ J. Holovský, S. De Wolf, P. Jirííček, and C. Ballif, Rev. Sci. Instrum. 86, 073108 (2015).

${ }^{13}$ T. Battaglia, S. Martin de Nicolas, S. De Wolf, X. Yin, M. Zheng, C. Ballif, and A. Javey, Appl. Phys. Lett. 104, 113902 (2014).

${ }^{14}$ M. Filipič, Z. C. Holman, F. Smole, S. De Wolf, C. Ballif, and M. Topič, J. Appl. Phys. 114, 074504 (2013).

${ }^{15}$ M. Boccard and Z. C. Holman, J. Appl. Phys. 118, 065704 (2015).

${ }^{16}$ R. Vasudevan, Z. Thanawala, L. Han, T. Buijs, H. Tan, D. Deligiannis, P. Perez-Rodriguez, I. A. Digdaya, W. A. Smith, M. Zeman, and A. H. M. Smets, Sol. Energy Mater. Sol. Cells 150, 82 (2016).

${ }^{17}$ O. Maslova, A. Brézard-Oudot, M. E. Gueunier-Farret, J. Alvarez, W. Favre, D. Muñoz, and J. P. Kleider, Appl. Phys. Lett. 103, 183907 (2013).

${ }^{18}$ Q. Wang, M. R. Page, E. Iwaniczko, Y. Xu, L. Roybal, R. Bauer, B. To, H.-C. Yuan, A. Duda, F. Hasoon, Y. F. Yan, D. Levi, D. Meier, H. M. Branz, and T. H. Wang, Appl. Phys. Lett. 96, 013507 (2010).

${ }^{19}$ J. V. Li, R. S. Crandall, D. L. Young, M. R. Page, E. Iwaniczko, and Q. Wang, J. Appl. Phys. 110, 114502 (2011).

${ }^{20}$ H. Uzu, M. Ichikawa, M. Hino, K. Nakano, T. Meguro, J. L. Hernández, H.-S. Kim, N.-G. Park, and K. Yamamoto, Appl. Phys. Lett. 106, 013506 (2015).

${ }^{21}$ E. Kobayashi, Y. Watabe, R. Hao, and T. S. Ravi, Appl. Phys. Lett. 106, 223504 (2015).

${ }^{22}$ E. Kobayashi, Y. Watabe, R. Hao, and T. S. Ravi, Prog. Photovoltaics 24, 1295 (2016).

${ }^{23}$ New Energy and Industrial Technology Development Organization (NEDO) and Kaneka Corporation, http://www.nedo.go.jp/english/news/ AA5en_100109.html for "World's Highest Conversion Efficiency of $26.33 \%$ Achieved in a Crystalline Silicon Solar Cell-A World First in a Practical Cell Size," 2016.

${ }^{24}$ S. W. Glunz, S. Rein, J. Y. Lee, and W. Warta, J. Appl. Phys. 90, 2397 (2001).

${ }^{25}$ J. Schmidt and K. Bothe, Phys. Rev. B 69, 024107 (2004).

${ }^{26}$ H. Dersch, J. Stuke, and J. Beichler, Appl. Phys. Lett. 38, 456 (1981).

${ }^{27}$ D. L. Staebler and C. R. Wronski, Appl. Phys. Lett. 31, 292 (1977).

${ }^{28}$ M. Stutzmann, W. B. Jackson, and C. C. Tsai, Phys. Rev. B 32, 23 (1985).

${ }^{29}$ H. M. Branz and M. Silver, Phys. Rev. B 42, 7420 (1990).

${ }^{30}$ D. Redfield and R. H. Bube, Phys. Rev. Lett. 65, 464 (1990).

${ }^{31}$ M. Stuckelberger, M. Despeisse, G. Bugnon, J.-W. Schüttauf, F.-J. Haug, and C. Ballif, J. Appl. Phys. 114, 154509 (2013).

${ }^{32}$ H. Plagwitz, B. Terheiden, and R. Brendel, J. Appl. Phys. 103, 094506 (2008).

${ }^{33}$ S. De Wolf, B. Demaurex, A. Descoeudres, and C. Ballif, Phys. Rev. B 83, 233301 (2011).

${ }^{34}$ E. M. El Mhamdi, J. Holovsky, B. Demaurex, C. Ballif, and S. De Wolf, Appl. Phys. Lett. 104, 252108 (2014).

${ }^{35}$ P. Mahtani, R. Varache, B. Jovet, C. Longeaud, J.-P. Kleider, and N. P. Kherani, J. Appl. Phys. 114, 124503 (2013).

${ }^{36}$ R. A. Sinton and A. Cuevas, Appl. Phys. Lett. 69, 2510 (1996).

${ }^{37}$ S. De Wolf and M. Kondo, J. Appl. Phys. 105, 103707 (2009).

${ }^{38}$ S. Olibet, E. Vallat-Sauvain, and C. Ballif, Phys. Rev. B 76, 035326 (2007).

${ }^{39}$ A. Richter, S. W. Glunz, F. Werner, J. Schmidt, and A. Cuevas, Phys. Rev. B 86, 165202 (2012). 
${ }^{40}$ M. Stutzmann, W. B. Jackson, and C. C. Tsai, Appl. Phys. Lett. 45, 1075 (1984).

${ }^{41}$ G. Agostinelli, A. Delabie, P. Vitanov, Z. Alexieva, H. F. W. Dekkers, S. De Wolf, and G. Beaucarne, Sol. Energy Mater. Sol. Cells 90, 3438 (2006).

${ }^{42}$ B. Liao, R. Stangl, T. Mueller, F. Lin, C. S. Bhatia, and B. Hoex, J. Appl. Phys. 113, 024509 (2013).
${ }^{43}$ J. G. Mihaychuk, J. Bloch, Y. Liu, and H. M. Van Driel, Opt. Lett. 20, 2063 (1995).

${ }^{44}$ D. A. Mehta, J. Appl. Phys. 43, 4631 (1972).

${ }^{45}$ M. Stutzmann, Philos. Mag. B 60, 531 (1989).

${ }^{46}$ A. Scuto, L. Valenti, S. Pierro, M. Foti, C. Gerardi, A. Battaglia, and S. Lombardo, Sol. Energy Mater. Sol. Cells 141, 203 (2015). 